Research Paper

\title{
Elevated Tumor Necrosis Factor-a-induced Protein 8-like 2 mRNA from Peripheral Blood Mononuclear Cells in Patients with Acute Ischemic Stroke
}

\author{
Yuan-Yuan Zhang ${ }^{1}$, Na-Na Huang ${ }^{1}$, Yan-Xin Zhao ${ }^{1}$, Yan-Shuang Li $^{1}$, Dong Wang ${ }^{1}$, Yu-Chen Fan ${ }^{\circledR}$, \\ Xiao-Hong Li ${ }^{1}$ \\ 1. Department of Neurology, Jinan Central Hospital affiliated to Shandong University, Jinan 250013, China \\ 2. Department of Hepatology, Qilu Hospital of Shandong University, Jinan 250012, China \\ $\triangle$ Corresponding authors: Prof. Xiao-Hong Li, MD, PhD. Department of Neurology, Jinan Central Hospital affiliated to Shandong University, Jiefang Road \\ 105\#, Jinan 250013, China. Email: xiaohong-li@sdu.edu.cn OR Dr. Yu-Chen Fan, MD, PhD. Department of Hepatology, Qilu Hospital of Shandong University, \\ Wenhuaxi Road 107\#, Jinan 250012, China. Email: fanyuchen@sdu.edu.cn \\ (c) Ivyspring International Publisher. This is an open access article distributed under the terms of the Creative Commons Attribution (CC BY-NC) license \\ (https://creativecommons.org/licenses/by-nc/4.0/). See http://ivyspring.com/terms for full terms and conditions.
}

Received: 2018.06.11; Accepted: 2018.10.18; Published: 2018.11.22

\begin{abstract}
Background: Tumor necrosis factor-a-induced protein 8-like 2 (TIPE2) is a novel regulator of immunity and protects against experimental stroke. However, the expression and function of TIPE2 in patients with acute ischemic stroke has not been well demonstrated.

Methods: A total of 182 consecutive patients with acute ischemic stroke and 40 healthy controls were included during November 2015 to June 2016. The mRNA levels of TIPE2, interleukin(IL)-1 $\beta$, IL-10, IL-6, nuclear factor(NF)-K $\beta$, activator protein(AP)-1, interferon(IFN)- $\mathrm{Y}$ and tumor necrosis factor(TNF)- $\alpha$ from peripheral blood mononuclear cells were determined using real time quantitative reverse transcriptase polymerase chain reaction. The severity of stroke was assessed using the National Institutes of Health Stroke Scale (NIHSS) score.

Results: The median mRNA levels of TIPE2, TNF- $\alpha$, AP-1, IFN- $\gamma$ and NF-K $\beta$ in patients with acute ischemic stroke were significantly higher than healthy controls (all $P<0.001$, respectively). Of note, TIPE2 mRNA showed an increasing trend on a time-dependent manner after the onset of stroke. Furthermore, TIPE2 mRNA was negatively associated with lesion volumes $(r=-0.23, P<0.01)$, NIHSS $(r=-0.15, P<0.05)$, TNF- $\alpha(r=-0.33, P<0.001)$, AP- $1(r=-0.28, P<0.001)$, IFN- $(r=-0.16, P<0.05)$ and NF-K $\beta(r=-0.13, P<0.05)$, but positively associated with IL-6 $(r=0.14, P<0.05)$ and IL-10 $(r=-0.31$, $P<0.001$ ). Hierarchy cluster analysis showed that TIPE2 mRNA has nearest membership with TNF- $\alpha$, followed by IL-6, NF-K $\beta$, AP-1, IL-10, IL-1 $\beta$ and IFN- $\gamma$. In addition, TIPE2 mRNA in survivals $(n=149)$ was significantly higher than nonsurvivals $(n=33)(P<0.001)$, and showed a great odd ratio ( $0.52,95 \%$ confidence interval: $0.349-0.760, P<0.001)$ on 3-month mortality.
\end{abstract}

Conclusions: TIPE2 mRNA contributed to the immune response of stroke and might be a potential biomarker for the mortality of acute ischemic stroke.

Key words: tumor necrosis factor-a-induced protein 8-like 2, acute ischemic stroke, tumor necrosis factor-a, National Institutes of Health Stroke Scale, mortality

\section{Introduction}

Acute ischemic stroke is a multiple complex condition due to an abrupt loss of blood volume to the brain which will result in the rapid death of the brain tissue[1]. Stroke associated immunity and inflammation are demonstrated to play critical roles in all the stages of disease progression, including acute event of stroke and long term recovery after stroke[2]. Usually, the post-stroke inflammatory responses can be classified into three phases: the acute phase refers to the clearance of dead cells and the brain tissue injury 
accompanied by the activation of microglia or macrophages in the first hours after the onset of stroke; the subacute phase refers to the infiltration of leukocytes into the brain and the resolution of inflammation in the first days. The later phase refers to tissue repair and glial scar by astrocytes and microglia in days and weeks after stroke [2-4]. When ischemic stroke happens, the brain injury would be initiated by hypoxia inducible factor-1a and Notch intracellular domain, which can lead to the production of pro-inflammatory cytokines and the activation of apoptotic signaling pathways[5]. Innate immunity is the first line of defense to brain injury, in which brain microglia/macrophage are activated and could produce a series of pro-inflammatory cytokines and chemokines to recruit peripheral immune cells into brain parenchyma[6, 7]. Unlike the innate immune system, the adaptive immune system is highly specific to antigen, which is associated with post-injury inflammatory response via the complex of T and B lymphocytes [3]. Actually, the first responder to brain injury is microglia/macrophage which is an essential modulator of immunologic responses after ischemic stroke[5]. However, the exact mechanism for orchestrating the modulation of immunological response post ischemic stroke has not been well demonstrated.

Tumor necrosis factor-a-induced protein 8-like 2 (TIPE2) is a recently identified negative modulator of inflammation in maintain immune homeostasis [8]. TIPE2 is highly expressed in resting macrophages and regulates the activation of the NF-KB and activator protein(AP)-1 signaling pathways in innate and adaptive immune response [8]. TIPE2 is capable of promoting M2 macrophage differentiation through the activation of PI3K-AKT signaling pathway during the resolution of inflammation and tissue repair [9]. In recent years, TIPE2 has been reported to play an important role in the development of infection [10], systemic lupus erythematosus [11, 12], hepatitis [13-15], colitis [16], and cancers [17-19]. In the mice model of ischemic stroke, the genetic ablation of tipe2 gene might contribute to more infiltration of macrophages/microglia, neutrophils and lymphocytes in the ischemic hemisphere, and increase the infarction volume of infarction and neurological dysfunction [20]. These findings firstly reported that TIPE2 is involved in the pathogenesis of stroke using ischemic stroke model [20]. In addition, TIPE2 has also been demonstrated to inhibit MAPK and NF-KB signaling pathways and reduce the production of pro-inflammatory cytokines in macrophages during myocardial ischemia/reperfusion injury [21]. Therefore, these results strongly suggested the potential role of TIPE2 in the inflammation and tissue repair of ischemic stroke.

However, the expression and function of TIPE2 in patients with acute ischemic stroke has not been well demonstrated. In this case-control study, a total of 182 consecutive patients with acute ischemic stroke and 40 age- and sex- well matched healthy controls were included. And then the mRNA levels of TIPE2, interleukin(IL)-1 $\beta$, IL-10, IL-6, nuclear factor(NF)-к $\beta$, activator protein(AP)-1, interferon(IFN)- $\gamma$ and tumor necrosis factor(TNF)- $\alpha$ from peripheral blood mononuclear cells were determined. Our results indicated that TIPE2 mRNA might contribute to the immune response of stroke and might be a potential biomarker for the mortality of patients with acute ischemic stroke.

\section{Patients and Methods}

\section{Patients and healthy controls}

During November 2015 to June 2016, 265 consecutive patients with naive acute ischemic stroke were collected in the Department of Neurology, Jinan Central Hospital affiliated to Shandong University, and 182 patients were finally included in this present study. The inclusive criteria were based on the clinical history, neurological symptoms and magnetic resonance imaging (MRI) according to the criteria of World Health Organization [22, 23]. The exclusive criteria consisted of intracranial hemorrhage, transient ischemic stroke, a recent history of surgery or myocardial infarction during the past three months, systemic inflammatory disease, aneurysmal subarachnoid hemorrhage, traumatic contusion, vascular malformation, malignant tumor, venous sinus thrombosis, and autoimmune diseases. During the same period, a total of 124 healthy subjects from the Physical Examination Center in our hospital have been collected and after matching age and sex, there were finally 40 patients were included as healthy controls. All the subjects signed the consent and the local ethics committee of the Jinan Central Hospital affiliated to Shandong University approved this study.

\section{Inclusion of demographic characteristics}

Generally, age, sex and body mass index (BMI) were collected as demographic characteristics. The National Institutes of Health Stroke Scale (NIHSS) score was calculated for identifying the severity of stroke [24]. Etiologically, the patients were classified by the Trial of Org 10,172 in Acute Stroke Treatment (TOAST) system: large-artery atherosclerosis, smallvessel occlusion, cardioembolism, and stroke of undetermined etiology (U) [25]. The clinical stroke syndrome was categorized using the classification criteria of the Oxfordshire Community Stroke Project (OCSP): total anterior circulation infarct (TACI), 
partial anterior circulation infarct (PACI), posterior circulation infarct (POCI), lacunar infarct (LACI) and uncertain[26]. The lesion volume was calculated by using the formula $0.5^{*} \mathrm{a}^{*} \mathrm{~b}^{*} \mathrm{c}$ in MRI with diffusion-weighted imaging (DWI) [27]. In detail, "a" means the largest cross-sectional diameter, and " $b$ " means a second diameter at the right angles to the first, as well as " $c$ " means the height of the ellipsoid. All the demographic characteristics were confirmed by a blinded neurologist (Prof. Yan-Xin Zhao).

\section{Laboratory tests}

A total of $3 \mathrm{ml}$ fasting blood were collected from each patients on the next morning after admitting to our stroke unit. Laboratory indicators including total cholesterol (TC), total triglycerides (TG), low-density lipoprotein (LDL), high-sensitivity C-reactive protein (Hs-CRP) and homocysteine (HCY) were performed according to standard methods in the clinical laboratory of our hospital. The estimated glomerular filtration rate (eGFR) was calculated according to the following formula: eGFR $(\mathrm{mL} / \mathrm{min} / 1.73 \mathrm{~m} 2)=175$ * creatinine -1.234 age $-0.179 *$ gender $($ male $=1$, female $=0.19$ ).

\section{RNA and cDNA Preparation from PBMC}

A total of $5 \mathrm{ml}$ citrate anticoagulated venous blood were provided from each patient. Peripheral blood mononuclear cells (PBMC) were collected by Fission Gradient centrifugation in Ficoll-Paque Plus (GE Healthcare, Uppsala, Sweden) and washed 3 times with phosphate buffered saline. Total RNA was extracted by TRIzol (Invitrogen, Carlsbad, CA). Two micrograms of RNA was reverse transcribed into cDNA using a first strand cDNA synthesis kit (Fermentas, Vilnius, Lithuania).

\section{Quantitative real-time PCR for TIPE2 mRNA level}

Real-time PCR was performed using Light cycler 480 (Roche Diagnostics, Mannheim, Germany). Particularly, the primers for real-time PCR are presented in Table 1. The procedure of Real-time PCR was performed using an SYBR Premix Ex TaqTM (Takara, Shiga, Japan) according to the manufacturer's instructions. The reaction condition of PCR was the following: denaturation at $95^{\circ} \mathrm{C}$ for $30 \mathrm{sec}$, followed by 40 cycles of $95^{\circ} \mathrm{C}$ for $5 \mathrm{sec}, 60^{\circ} \mathrm{C}$ for $30 \mathrm{sec}$, and $72^{\circ} \mathrm{C}$ for $30 \mathrm{sec}$. Each sample was carried out three times. The results were determined using the comparative (2- $\triangle \triangle \mathrm{Ct})$ method.

\section{Statistical analysis}

The data was expressed as percentages (\%) for dichotomous variables and medians [interquartile range (IQR)] for continuous variables. The estimated statistical power was 0.99 based on a two side $<0.05$ significance level when we set the assumed median level to 5.0 for TIPE2 mRNA level in patients and 3.0 for healthy controls, and set the ratio for case/control with 4:1 under the current total sample size(222). The Mann-Whitney U-test and the $\mathrm{X}$ 2-test were used to compare the two groups. Comparison within each two groups was performed using SNK $t$ test after analysis of variance for the differences in the AIS patients with different time stages. Correlations of TIPE2 mRNA level with laboratory variables and TIPE2 associated cytokines mRNA levels were determined using Pearson correlation coefficient. Hierarchical cluster analysis was performed to build a membership of clusters of TIPE2 and its associated cytokines. The effects of TIPE2 mRNA and TIPE2 associated cytokines were estimated as odds ratio (OR) with $95 \%$ confidence interval (CI) on 3-month mortality using full steps logistic regression models. All analyses were performed using Empower(R) (www.empowerstats.com, X\&Y solutions, IncBoston, MA) and R (http://www.R-project.org). Statistical significance was defined as $P<0.05$.

Table 1. Primers sequence for TIPE2 and its associated cytokines using RT-PCR.

\begin{tabular}{|c|c|}
\hline Gene & Primer sequences $\left(5^{\prime}-3^{\prime}\right)$ \\
\hline \multirow[t]{2}{*}{ TIPE2 } & Forward GGAACATCCAAGGCAAGACTG \\
\hline & Reverse AGCACСТCACTGCTTGTCTCATC \\
\hline \multirow[t]{2}{*}{ TNF- $\alpha$} & Forward AAGCCTGTAGCCCATGTTGT \\
\hline & Reverse CAGATAGATGGGCTCATACC \\
\hline \multirow[t]{2}{*}{ IFN- $\gamma$} & Forward GCAGAGCCAAATTGTCTCCT \\
\hline & Reverse ATGCTCTTCGACCTCGAAAC \\
\hline \multirow[t]{2}{*}{ AP-1 } & Forward CTCAGCAACTTCAACCCG \\
\hline & Reverse GCACTTGGAGGCAGCCCG \\
\hline \multirow[t]{2}{*}{ NF-kB } & Forward CACAGATACCACTAAGACGCACC \\
\hline & Reverse GACCGCATTCAAGTCATAGTCC \\
\hline \multirow[t]{2}{*}{ IL-6 } & Forward ACСCCTGACCCAACCACAAAT \\
\hline & Reverse AGCTGCGCAGAATGAGATGAGTT \\
\hline \multirow[t]{2}{*}{ IL-10 } & Forward ATGCTTCGAGATCTCCGAGA \\
\hline & Reverse AAATCGATGACAGCGCCGTA \\
\hline \multirow[t]{2}{*}{ IL-1 $\beta$} & Forward AAACAGATGAAGTGCTCCTTCCAGG \\
\hline & Reverse TGGAGAACACСАСТTGTTGCTCCA \\
\hline \multirow[t]{2}{*}{$\beta$-actin } & Forward ATGGGTCAGAAGGATTCCTATGTG \\
\hline & Reverse CTTCATGAGGTAGTCAGTCAGGTC \\
\hline
\end{tabular}

\section{Results}

\section{Descriptive Characteristics of Patients with acute ischemic stroke and healthy controls}

The inclusive and exclusive processes of AIS patients and healthy controls have been described in Figure 1. Initially, a total of 265 patients were newly diagnosed with ischemic stroke and a total of 69 patients have been excluded (23 patients with transient ischemic attack, 24 patients with more than 24 hours at admission from the onset of stroke symptom, and 22 patients with hemorrhage stroke). Among the 
196 remaining patients, there were 5 patients who rejected the informed consent, 5 patients with severe systemic bacterial infection, and 5 patients with malignant tumor. Finally, a total of 182 patients were included in this present study. During the same period, a total of 124 healthy subjects from the Physical Examination Center in our hospital have been collected and after matching age and sex, there were finally 40 patients were included as healthy controls.

The descriptive characteristics of AIS patients and healthy controls have been shown in Table 2 . Notable, the sex and age of AIS patients and healthy controls were well matched. The levels of BMI, HsCRP, GFR, FBG, TG, TC, LDL, and HCY were significantly higher than those in healthy controls $(P<0.05$, respectively). In the AIS patients, majority of patients were punctured for the determination of TIPE2 mRNA and associated cytokines mRNA levels after the onset at $6-12$ hours $(n=58,31.87 \%)$, followed by $12-18$ hours $(n=45,24.73 \%), 18-24$ hours $(n=42,23.08$ $\%)$, more than 24 hours $(\mathrm{n}=29,15.93 \%)$, and less than 6 hours $(\mathrm{n}=8,4.4 \%)$.

\section{Comparison of TIPE2 and associated cytokines mRNA levels in patients with acute ischemic stroke and healthy controls}

The median relative expression of TIPE2 mRNA in patients with acute ischemic stroke was 4.75 with IQR (3.69-6.38), which was significantly higher that than in healthy controls (2.22, IQR: 1.30-4.24; P<0.001) (Table 2, Figure 2A). Furthermore, we have determined the relative expression of TIPE2 associated cytokines, including IL-1 $\beta$, IL-10, IL-6, NF-к $\beta$, AP-1, IFN- $\gamma$ and TNF- $\alpha$. In patients with acute ischemic stroke, the relative mRNA levels of TNF- $\alpha$, AP-1, IFN- $\gamma$ and NF-к $\beta$ were significantly elevated compared with those in healthy controls [TNF- $\alpha, 3.74$ (2.40-5.48) versus 2.16(1.68-3.69), $P<0.001$; AP-1, 4.44 (3.12-5.91) versus 4.00(2.11-5.65), $P<0.05$; IFN- $\gamma, 4.46$ (3.06-5.94) versus 2.63(1.63-3.93), $P<0.001 ; \mathrm{NF}-\mathrm{k} \beta, 2.91$ (2.04-3.92) versus 0.68(0.44-1.04), $P<0.001]$ (Table 2, Figure 2C). However, there were no significant differences of IL-1 $\beta$, IL-10 and IL-6 in patients with acute ischemic stroke and healthy controls [IL-1 $\beta, 4.50$ (2.93-6.19) versus 3.38(1.81-5.25), $P>0.05$; IL-6, 4.00 (2.58-7.89) versus 3.05(1.48-7.67), $P>0.05$; IL-10, 3.58 (1.85-6.96) versus 1.75(0.75-3.59), $P>0.05]$ (Table 2, Figure 2C).

\section{Dynamic profiles of TIPE2 and its associated cytokine mRNA levels in AIS patients with different time stages}

According to the time from the symptom onset to the time of blood sampling, AIS patients were classified into 5 groups at the points of 6 hours, 12 hours, 18 hours and 24 hours. In Figure 2B showed an increasing trend of TIPE2 mRNA level on the timedependent manner. The TIPE2 mRNA level in patients with $>24$ hours was significant higher than that in patients with $<6$ hours and 6-12 hours $(P<0.01$, respectively). In addition, patients with 12-18 hours have significant higher level of TIPE2 mRNA compared with that in patients with 6-12 hours $(P<0.05)$. However, we did not found significant differences of IL-1 $\beta$, IL-10, IL-6, NF-k $\beta$, AP-1, IFN- $\gamma$ and TNF- $\alpha$ mRNA levels in AIS patients with different time stages (all $P>0.05$, respectively) (Figure 2D).

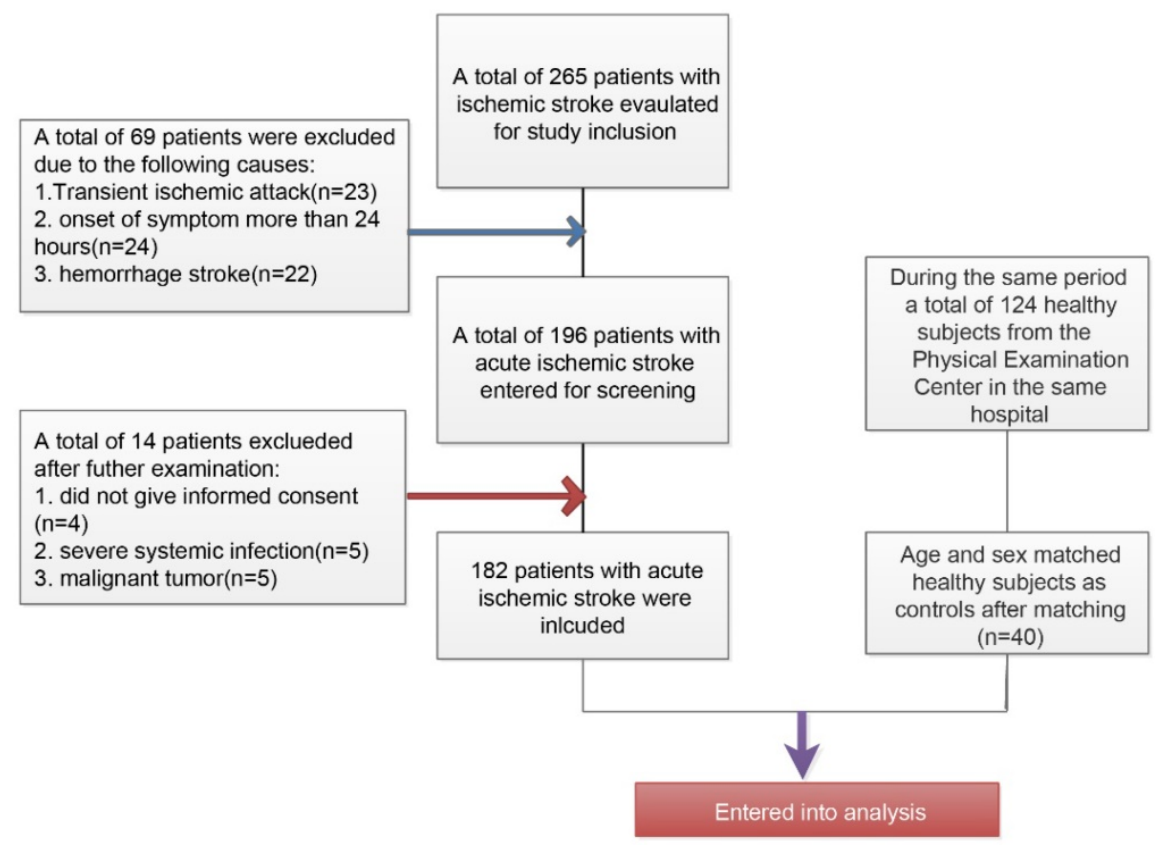

Figure 1. Flowchart for the inclusion of study patients with acute ischemic stroke and healthy controls 


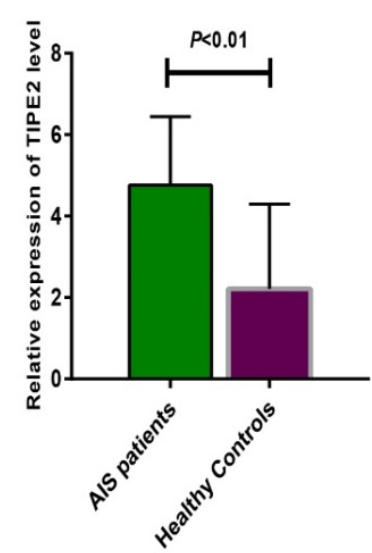

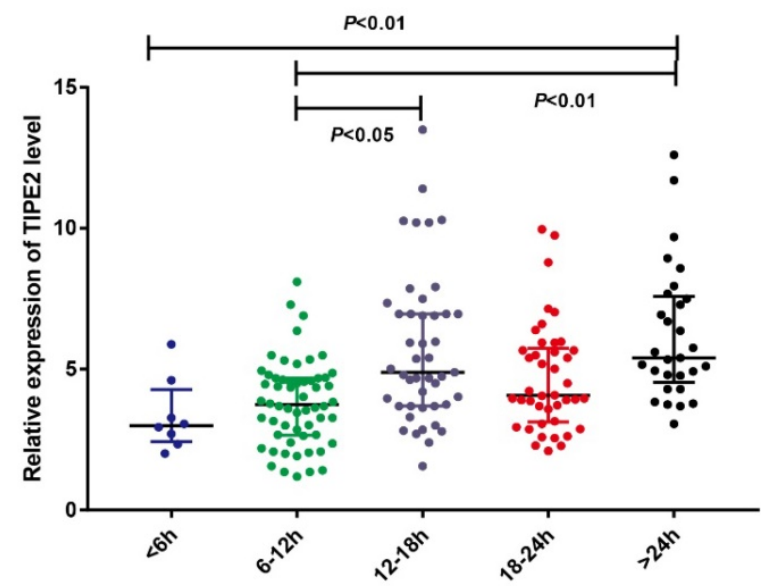

C

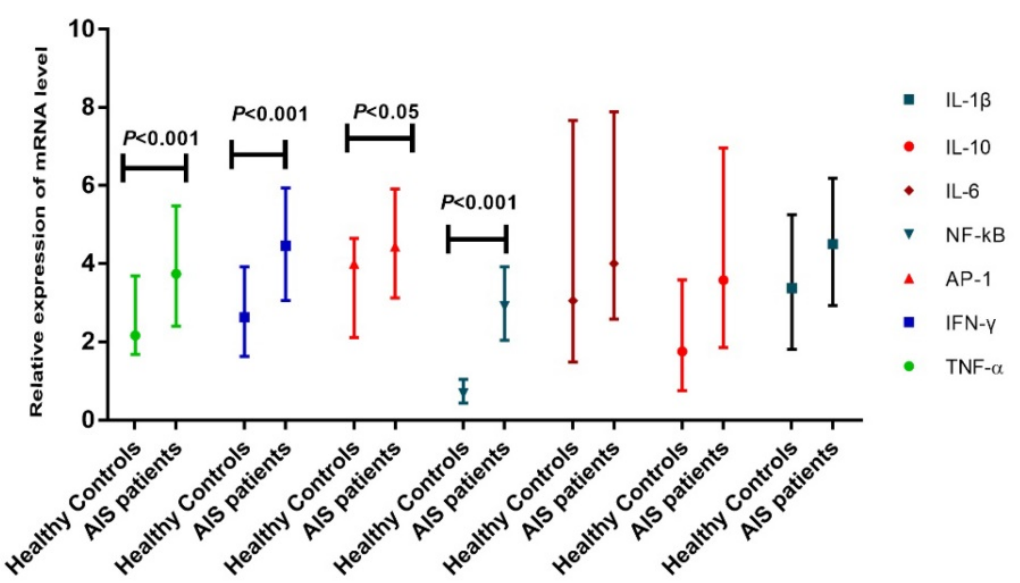

D

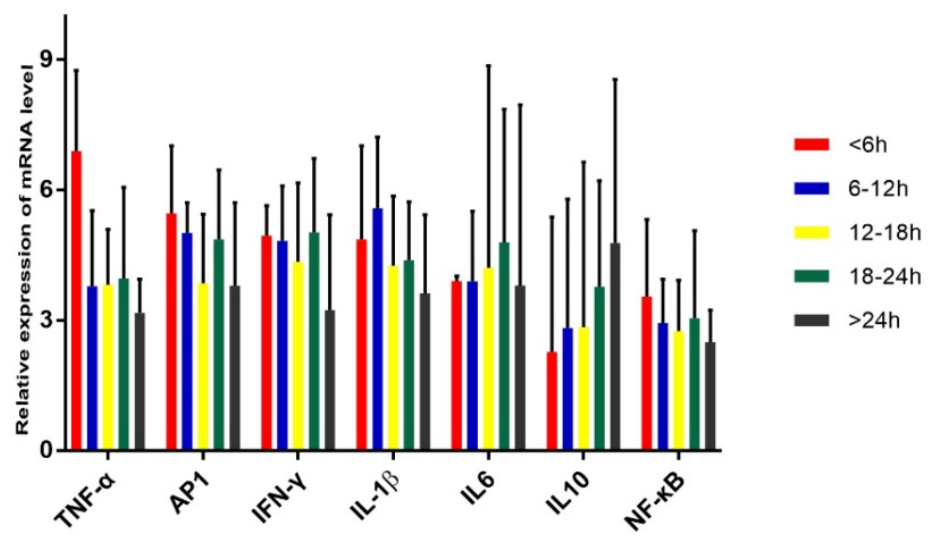

Figure 2. Comparsion of TIPE2 mRNA and its associated cytokines in patients with acute ischemic stroke and healthy controls. The gene expressions of TIPE2, TNF- $\alpha, A P-1$, IFN- $y$ and NF-K $\beta$ in patients with acute ischemic stroke were significantly higher that than in healthy controls (A, C). (B) showed an increasing trend of TIPE2 mRNA level on the time-dependent manner. However, we did not found significant differences of IL-1 $\beta$, IL-10, IL-6, NF-K $\beta$, AP-1, IFN- $\gamma$ and TNF- $\alpha$ mRNA levels in AIS patients with different time stage (D).

\section{Associations of TIPE2 mRNA levels with laboratory variables in patients with acute ischemic stroke}

To determine the potential effect of TIPE2 mRNA, we first compared the characteristics of patients with acute ischemic stroke stratified by the median of TIPE2 (4.75) in Table 3. The median value of lesion volumes was $1.50(0.34-20.25) \mathrm{mL}$ in patients with TIPE2 mRNA <4.75, which was significantly higher than that in patients with TIPE2 $>=4.75$ [0.50(0.10-1.90), $P<0.05]$. Meanwhile, the median value of NIHSS was 5.00(2.50-11.50) in patients with TIPE2 mRNA <4.75, which was significantly higher than that in patients with TIPE2 $>=4.75[3.00(2.00-$ 7.00), $P<0.01]$. Furthermore, Pearson correlation analysis was performed and there was significantly negative correlations with TIPE2 mRNA and lesion volumes $(\mathrm{r}=-0.23, P<0.01), \mathrm{LDH}(\mathrm{r}=-0.05, P<0.05)$ and 
NIHSS $(\mathrm{r}=-0.15, \quad P<0.05)$ in Figure $3 \mathrm{~B}$ and $3 \mathrm{D}$. However, we did not find any significant associations of TIPE2 mRNA with $\operatorname{HsCRP}(\mathrm{r}=-0.03, P>0.05)$, FBG $(\mathrm{r}=0.03, P>0.05), \mathrm{TG}(\mathrm{r}=-0.08, P>0.05), \mathrm{TC}(\mathrm{r}=-0.01$, $P>0.05)$ or $\operatorname{GFR}(\mathrm{r}=-0.01, P>0.05)$ (Figure $3 \mathrm{~A}, 3 \mathrm{~B}$ and $3 \mathrm{D})$.

Table 2. Basic characteristics of patients with acute ischemic stroke and healthy controls

\begin{tabular}{|c|c|c|c|}
\hline Characteristics & AIS patients(n=182) & Healthy Controls $(n=40)$ & $P$ value \\
\hline Sex & & & 0.426 \\
\hline Female & $92(50.55 \%)$ & $23(57.50 \%)$ & \\
\hline Male & $90(49.45 \%)$ & $17(42.50 \%)$ & \\
\hline Age, Years & $68.00(59.00-75.00)$ & $64.50(56.50-71.00)$ & 0.101 \\
\hline $\mathrm{BMI}, \mathrm{kg} / \mathrm{m} 2$ & $27.00(25.00-29.00)$ & $24.70(23.00-26.00)$ & $<0.001$ \\
\hline HSCRP,mg/dL & $6.40(4.73-10.02)$ & $5.80(4.50-6.40)$ & $<0.001$ \\
\hline $\begin{array}{l}\text { eGFR, } \\
\mathrm{mL} / \mathrm{min} / 1.73 \mathrm{~m} 2\end{array}$ & $89.00(77.00-100.50)$ & $79.00(73.50-91.25)$ & 0.021 \\
\hline $\mathrm{FBG}, \mathrm{mmol} / \mathrm{L}$ & $5.70(5.00-7.30)$ & $5.30(4.85-5.73)$ & 0.003 \\
\hline $\mathrm{TG}, \mathrm{mmol} / \mathrm{L}$ & $1.46(0.90-2.07)$ & $0.91(0.72-1.40)$ & $<0.001$ \\
\hline $\mathrm{TC}, \mathrm{mmol} / \mathrm{L}$ & $4.60(3.93-5.47)$ & $5.10(4.50-5.80)$ & 0.037 \\
\hline $\mathrm{LDL}, \mathrm{mmol} / \mathrm{L}$ & $3.00(2.57-3.70)$ & $2.86(2.69-2.97)$ & 0.04 \\
\hline $\mathrm{HCY}, \mathrm{umol} / \mathrm{L}$ & $11.85(9.77-15.00)$ & $10.00(8.00-13.00)$ & 0.011 \\
\hline NIHSS & $4.00(2.00-8.00)$ & NA & NA \\
\hline Time Onset,hours & & & NA \\
\hline$<6$ & $8(4.40 \%)$ & NA & \\
\hline$>=6,<12$ & $58(31.87 \%)$ & NA & \\
\hline$>=12,<18$ & $45(24.73 \%)$ & NA & \\
\hline$>=18,<24$ & $42(23.08 \%)$ & NA & \\
\hline$>=24$ & $29(15.93 \%)$ & NA & \\
\hline $\begin{array}{l}\text { Lesion volumes, } \\
\mathrm{mL}\end{array}$ & $0.93(0.20-7.88)$ & NA & \\
\hline TIPE2 & 4.75 (3.69-6.38) & $2.22(1.30-4.24)$ & $<0.001$ \\
\hline TNF- $\alpha$ & $3.74(2.40-5.48)$ & $2.16(1.68-3.69)$ & $<0.001$ \\
\hline AP-1 & $4.44(3.12-5.91)$ & $4.00(2.11-4.65)$ & 0.014 \\
\hline IFN-Y & $4.46(3.06-5.94)$ & $2.63(1.63-3.92)$ & $<0.001$ \\
\hline IL-1 $\beta$ & $4.50(2.93-6.19)$ & $3.38(1.81-5.25)$ & 0.177 \\
\hline IL6 & $4.00(2.58-7.89)$ & 3.05 (1.48-7.67) & 0.66 \\
\hline IL10 & $3.58(1.85-6.96)$ & $1.75(0.75-3.59)$ & 0.124 \\
\hline NF-кB & $2.91(2.04-3.92)$ & $0.68(0.44-1.04)$ & $<0.001$ \\
\hline
\end{tabular}

\section{Associations of TIPE2 mRNA levels with TIPE2 associated cytokines in patients with acute ischemic stroke}

In table 3, the median values of TNF- $\alpha$, AP-1, IFN- $\gamma$ and NF- $\mathrm{K} \beta$ in patients with TIPE2 mRNA $<4.75$ were significant higher than that in patients with TIPE2 mRNA >=4.75[TNF- $\alpha, 4.95(3.68-7.46)$ versus 2.64(1.18-3.85), $P<0.001$; AP-1, 4.86(3.78-6.92) versus 3.85(1.92-5.42), $P<0.001$; IFN- $\gamma, 4.86(3.75-6.90)$ versus 3.21(1.86-5.29), $P<0.001$; NF- $\beta \beta, 3.60(2.57-5.16)$ versus 2.18(1.05-3.11), $P<0.001]$. Meanwhile, the median value of IL-10 in patients with TIPE2 mRNA $<4.75$ were significant lower than that in patients with TIPE2 mRNA $>=4.75[2.48(1.52-4.24)$ versus 5.09(2.59$8.50), P<0.001]$. In Figure $3 \mathrm{~A}$, Pearson correlation analysis demonstrated that TIPE2 mRNA level was significantly negatively associated with TNF- $\mathrm{a}(\mathrm{r}=$ -0.33, $P<0.001)$ AP-1 $(\mathrm{r}=-0.28, P<0.001)$, IFN- $\gamma(\mathrm{r}=-0.16$, $\mathrm{P}<0.05)$ and NF- $\mathrm{k} \beta(\mathrm{r}=-0.13, P<0.05)$, but significantly positively associated with IL-6 $(\mathrm{r}=0.14, P<0.05)$ and
IL-10( $\mathrm{r}=-0.31, P<0.001)$. However, there were no significant associations between TIPE2 mRNA and IL-1 $\beta(r=-0.04, P>0.05)$. Furthermore, hierarchy cluster analysis showed that TIPE2 mRNA has nearest membership with TNF- $\alpha$, followed by IL-6, NF-k $\beta$, AP-1, IL-10, IL-1 $\beta$ and IFN- $\gamma$ in Figure 3C.

\section{TIPE2 and its associated cytokines mRNA levels in survival and nonsurvivals in patients with acute ischemic stroke}

After the 3-month treatment and follow up, a total of 33 patients died and the mortality rate was $18.13 \%$. In table 3 , the mortality rate of AIS patients with TIPE2 mRNA<4.75 (31.87\%) was significantly higher than that of AIS patients with TIPE2 mRNA $>=4.75(4.40 \%, P<0.001)$. As illustrated in Figure 4A, violin plot showed that the median of TIPE2 mRNA in survivals [5.31(3.87-6.96)] was significantly higher than that in nonsurvivals [3.06(2.19-4.35), $P<0.001]$, as well as the same trend for IL-10 [3.80(1.96-7.55) versus $2.40(1.50-4.65), P<0.05]$ in bean plot of Figure $4 \mathrm{~B}$. However, the medians of TNF- $\alpha$, AP- 1, IFN- $\gamma$ and NF- $\mathrm{k} \beta$ mRNA levels in survivals were significantly lower than that in nonsurvivals[TNF-a, 3.42(2.20-4.86) versus 5.67(4.67-7.72), $P<0.001$; AP-1, 4.08(2.80-5.79) versus 5.40 (4.44-8.10), $P<0.001$; IFN- $\gamma$, 4.14(2.85-5.76) versus 5.52(4.35-7.77), $P<0.01$; NF-к $\beta, 2.58(1.80-3.76)$ versus 3.60(2.98-4.08), $P<0.05]$. Furthermore, we did not find any significant differences of IL-1 $\beta$ and IL-6 mRNA levels between survivals and nonsurvivals [IL-1 $\beta, 4.47(3.09-6.03)$ versus 4.65(2.48-6.60), $P>0.05$; IL-6, 4.05(2.60-8.00) versus 3.91(2.56-7.12), $P>0.05]$.

In addition, the ORs with $95 \% \mathrm{CI}$ of TIPE 2 mRNA and TIPE2 associated cytokines on mortality were estimated. As illustrated in Figure 5, TIPE2 mRNA showed the greatest $\mathrm{OR}(0.52,95 \% \mathrm{CI}: 0.349-0.760)$, $P<0.001$ ) in all the ORs for IL-1 $\beta$ (OR $0.90,95 \% \mathrm{CI}$ 0.773-1.052, $P>0.05)$, IL-10(OR 0.99, 95\% CI 0.859-1.140, $P>0.05)$, IL-6(OR 0.99, 95\%CI 0.908-1.069, P>0.05), NF-к $\beta$ (OR 0.89, 95\%CI 0.702-1.136, $P>0.05)$, AP-1(OR 0.95, 95\%CI 0.692-1.517, $P>0.05$ ), IFN-ץ (OR 1.06, $95 \%$ CI 0.852-1.319, $P>0.05)$ and TNF-a(OR 1.17, 95\%CI 0.902-1.517, $P>0.05)$, suggesting that TIPE2 mRNA might be a potential biomarker for the mortality of acute ischemic stroke.

\section{Discussion}

Currently, immunity and inflammation play critical roles in acute event of stroke [2]. However, the exact mechanism for the modulation of immunological response in ischemic stroke has not been well demonstrated. In the mice model of ischemic stroke, knockout of tipe2 gene contributed to more infiltration of macrophages/ microglia, neutrophils and lymphocytes in the ischemic hemisphere, and 
increase the infarction volume of infarction and neurological dysfunction [20]. In addition, TIPE2 has also been demonstrated to inhibit MAPK and NF-KB signaling pathways and reduce the production of pro-inflammatory cytokines in macrophages during myocardial ischemia/reperfusion injury [21]. However, the expression and function of TIPE2 in patients with acute ischemic stroke has not been well demonstrated. In this case-control study, we reported
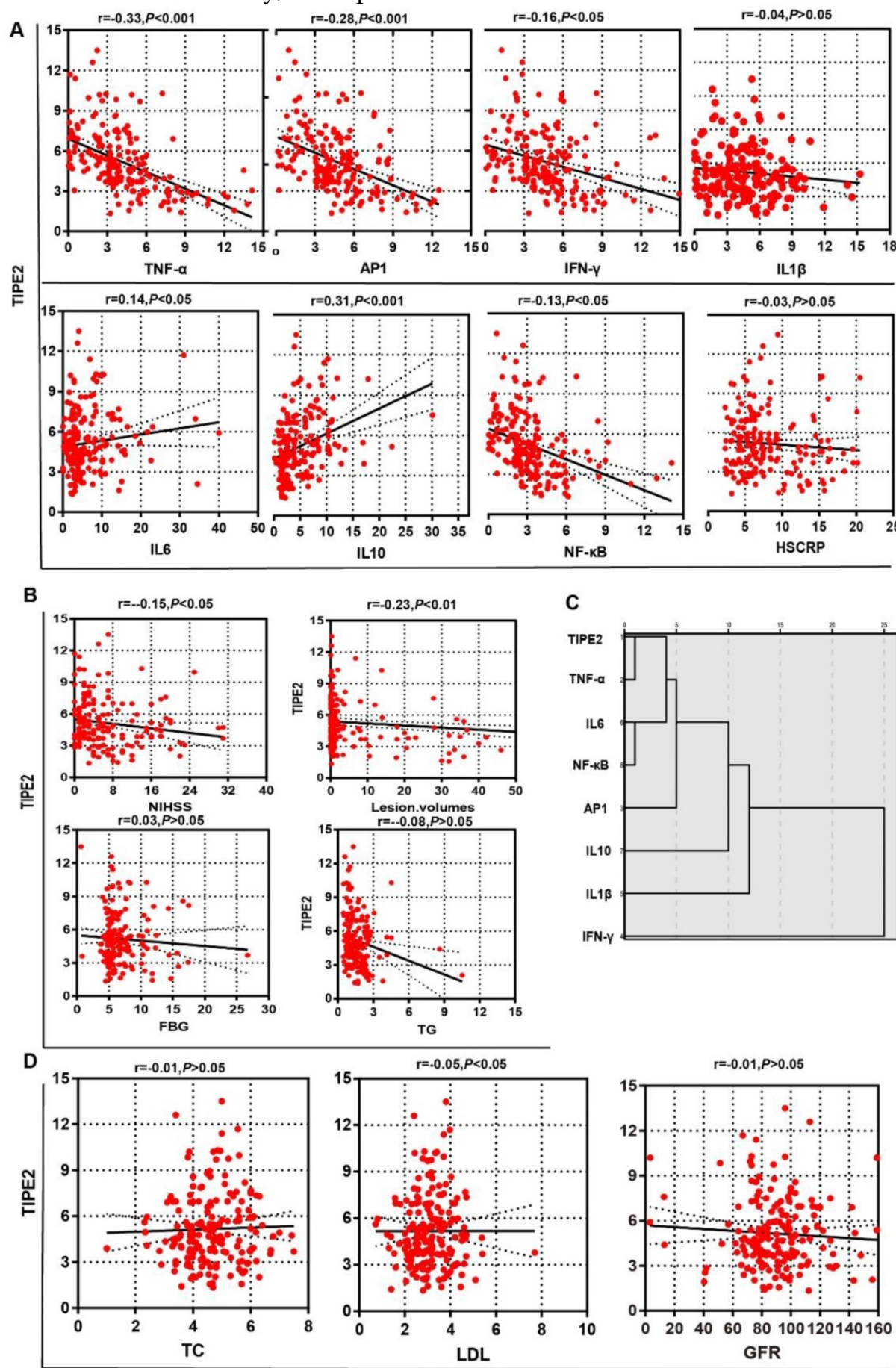

Figure 3. Associations of TIPE2 mRNA level with clinical parameters in patients with acute ischemic stroke. There was significantly negative correlations with TIPE2 mRNA and lesion volumes, LDH and NIHSS (B, D). However, we did not find any significant associations of TIPE2 mRNA with HsCRP, TG, TC or GFR (Figure A, B and D). TIPE2 mRNA level was significantly negatively associated with TNF- $\alpha, A P-1$, IFN- $\gamma$ and NF-K $\beta$, but significantly positively associated with IL-6 and IL-10(A). Furthermore, hierarchy cluster analysis showed that TIPE2 mRNA has nearest membership with TNF- $\alpha$, followed by IL-6, NF-K $\beta$, AP-1, IL-10, IL-1 $\beta$ and IFN- $\gamma(C)$. 
A
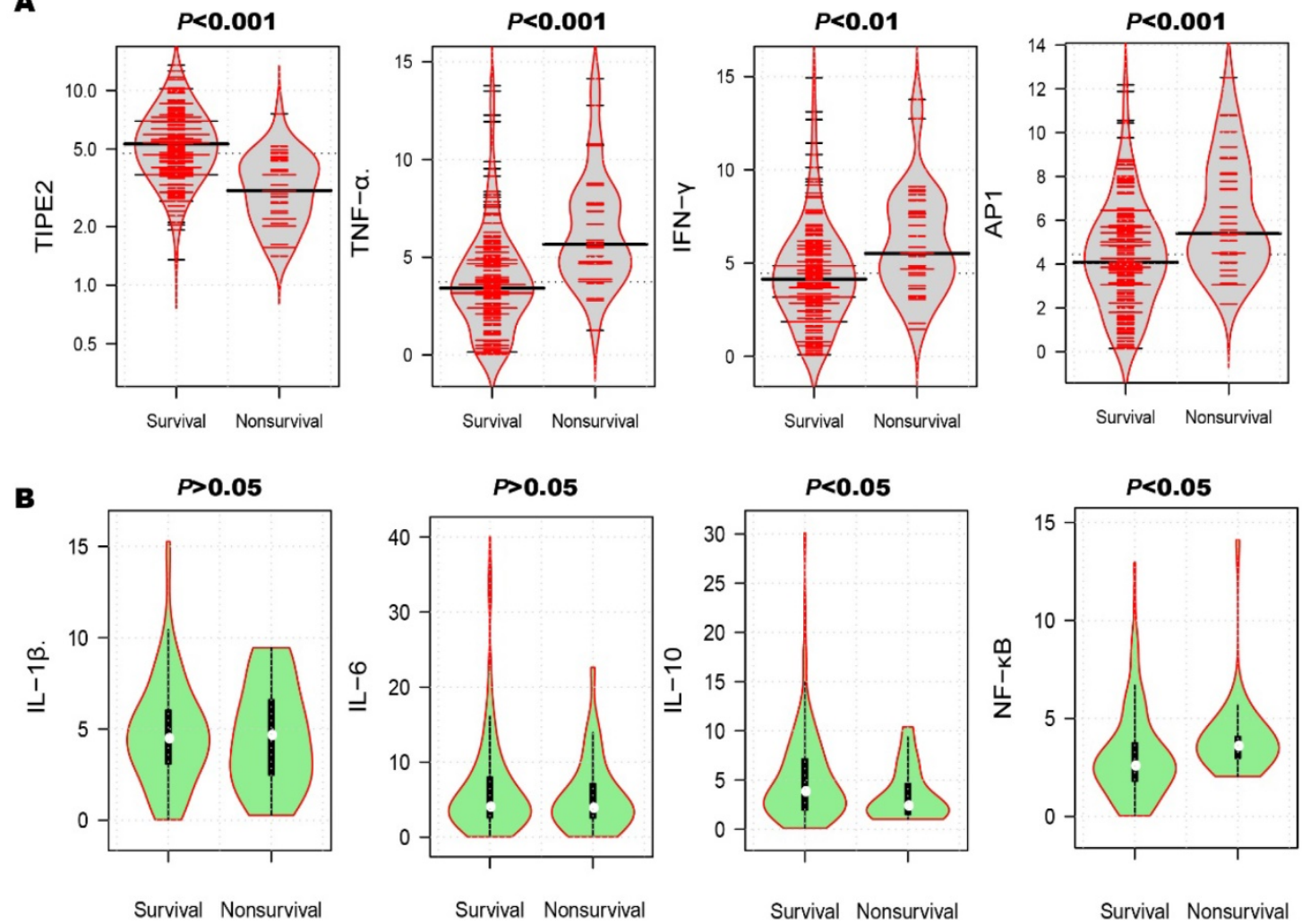

Figure 4. Comparison of TIPE2 mRNA and its associated cytokines in survivals and nonsurvivals. The median of TIPE2 mRNA in survivals was significantly higher than that in nonsurvivals (A), as well as the same trend for IL-10(B). However, the medians of TNF- $\alpha$, AP-1, IFN- $y$ and NF-K $\beta$ mRNA levels in survivals were significantly lower than that in nonsurvivals (A). Furthermore, we did not find any significant differences of IL-1 $\beta$ and IL-6 mRNA levels between survivals and nonsurvivals (B).

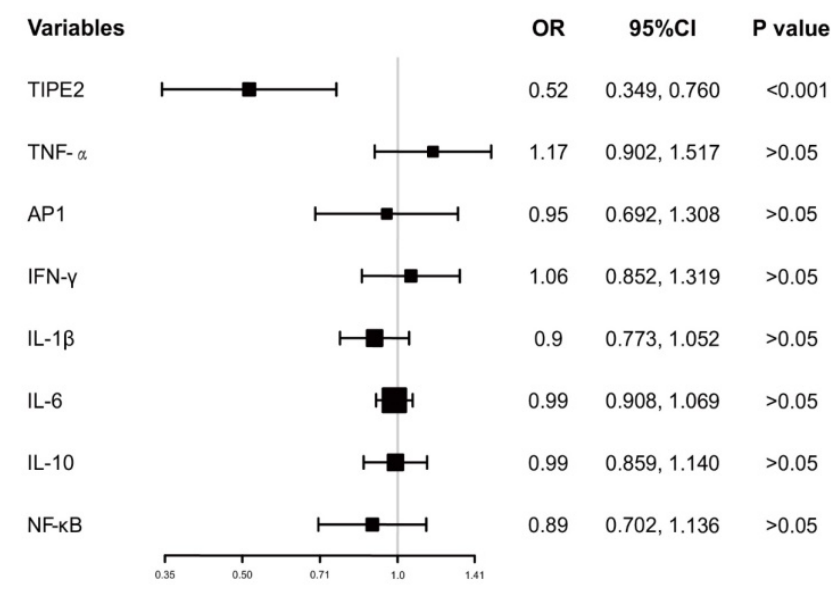

Figure 5. Odd raitos of TIPE2 and its associated cytokines on the mortality after 3 months.

According to the time from the symptom onset to the time of blood sampling, we classified the acute ischemic stroke patients into 5 groups basing the time within the first two days after the stroke onset. Importantly, the results showed an increasing trend of TIPE2 mRNA level on the time-dependent manner and strongly suggested that TIPE2 involved in the pathogenesis and progression of acute ischemic stroke. TIPE2 was firstly identified as negative modulator of inflammation and has been reported to be highly expressed in resting macrophages [8]. TIPE2 is capable of promoting M2 macrophage differentiation through the activation of PI3K-AKT signaling pathway during the resolution of inflammation and tissue repair [9]. The M1 subtype of macrophage can promote the activation of NF-kB and release pro-inflammatory cytokines, which contributes to the injury of the brain [28]. The M2 subtype of macrophage can secret the anti-inflammatory cytokines including IL-33 and IL-10, which can exert the protective role on the brain tissue from ischemia and hypoxia [28]. It has been considered that the appearance of M1 subtype in the early stage is deleterious, which can activate the location of NF-KB to produce pro-inflammatory cytokines, such as TNF- $\alpha$, IL-1 $\beta$, and NO[29]. The hypothesis has also been supported by our data that the relative mRNA levels of TNF- $\alpha$, AP- 1, IFN- $\gamma$ and NF- $\mathrm{k} \beta$ were significantly elevated compared with those in healthy controls. 
Table 3. Characteristics of patients with acute ischemic stroke stratified by the median of TIPE2.

\begin{tabular}{|c|c|c|c|}
\hline Characteristic & $\begin{array}{l}\text { TIPE2 } \\
\text { mRNA<4.75(n=91) }\end{array}$ & $\begin{array}{l}\text { TIPE2 mRNA } \\
>=4.75(\mathrm{n}=91)\end{array}$ & P-value \\
\hline Sex & & & 0.767 \\
\hline Female & $45(49.45 \%)$ & $47(51.65 \%)$ & \\
\hline Male & $46(50.55 \%)$ & $44(48.35 \%)$ & \\
\hline Age,Years & $69.00(61.50-76.00)$ & $66.00(56.50-75.00)$ & 0.293 \\
\hline $\mathrm{BMI}, \mathrm{kg} / \mathrm{m} 2$ & $27.90(26.00-29.00)$ & $27.00(25.00-29.05)$ & 0.366 \\
\hline Time Onset,hours & & & 0.018 \\
\hline$<6$ & $5(5.49 \%)$ & $3(3.30 \%)$ & \\
\hline$>=6,<12$ & $36(39.56 \%)$ & $22(24.18 \%)$ & \\
\hline$>=12,<18$ & $21(23.08 \%)$ & $24(26.37 \%)$ & \\
\hline$>=18,<24$ & $22(24.18 \%)$ & $20(21.98 \%)$ & \\
\hline$>=24$ & $7(7.69 \%)$ & $22(24.18 \%)$ & \\
\hline Lesion volumes,mL & $1.50(0.34-20.25)$ & $0.50(0.10-1.90)$ & 0.012 \\
\hline $\begin{array}{l}\text { Lesion volumes } \\
\text { classification }\end{array}$ & & & 0.318 \\
\hline Large & $16(17.58 \%)$ & $9(9.89 \%)$ & \\
\hline Middle & $4(4.40 \%)$ & $4(4.40 \%)$ & \\
\hline Small & $71(78.02 \%)$ & $78(85.71 \%)$ & \\
\hline Before and after cycle & & & 0.111 \\
\hline LACS & $1(1.10 \%)$ & $5(5.49 \%)$ & \\
\hline POCS & $20(21.98 \%)$ & $28(30.77 \%)$ & \\
\hline TACS & $62(68.13 \%)$ & $48(52.75 \%)$ & \\
\hline PACS & $8(8.79 \%)$ & $10(10.99 \%)$ & \\
\hline NIHSS & $5.00(2.50-11.50)$ & $3.00(2.00-7.00)$ & 0.008 \\
\hline $\mathrm{HSCRP}, \mathrm{mg} / \mathrm{dL}$ & $7.10(5.15-12.40)$ & $6.20(4.60-8.40)$ & 0.075 \\
\hline $\mathrm{GFR}, \mathrm{mL} / \mathrm{min} / 1.73 \mathrm{~m} 2$ & 87.00 (76.00- 99.25) & $0.50(78.00-103.00)$ & 0.607 \\
\hline $\mathrm{FBG}, \mathrm{mmol} / \mathrm{L}$ & $5.70(4.90-7.50)$ & $5.60(5.10-7.00)$ & 0.424 \\
\hline $\mathrm{TG}, \mathrm{mmol} / \mathrm{L}$ & $1.60(0.97-2.10)$ & $1.23(0.90-1.95)$ & 0.115 \\
\hline $\mathrm{TC}, \mathrm{mmol} / \mathrm{L}$ & $4.60(3.90-5.42)$ & $4.61(3.97-5.45)$ & 0.743 \\
\hline $\mathrm{LDL}, \mathrm{mmol} / \mathrm{L}$ & $3.00(2.54-3.73)$ & $3.10(2.60-3.65)$ & 0.535 \\
\hline HCY,umol/L & $11.80(9.60-15.30)$ & $11.90(9.80-14.60)$ & 0.475 \\
\hline TNF- $\alpha$ & $4.95(3.68-7.46)$ & $2.64(1.18-3.85)$ & $<0.001$ \\
\hline AP-1 & $4.86(3.78-6.92)$ & $3.85(1.92-5.42)$ & $<0.001$ \\
\hline IFN-Y & $4.86(3.75-6.90)$ & $3.21(1.86-5.29)$ & $<0.001$ \\
\hline $\mathrm{IL}-1 \beta$ & $4.67(3.03-7.08)$ & $4.38(2.79-5.71)$ & 0.167 \\
\hline IL6 & $3.89(2.64-6.00)$ & $4.30(2.56-8.59)$ & 0.073 \\
\hline IL10 & $2.48(1.52-4.24)$ & $5.09(2.59-8.50)$ & $<0.001$ \\
\hline NF-кB & $3.60(2.57-5.16)$ & $2.18(1.05-3.11)$ & $<0.001$ \\
\hline Outcome & & & $<0.001$ \\
\hline Survival & $62(68.13 \%)$ & $87(95.60 \%)$ & \\
\hline Nonsurvival & $29(31.87 \%)$ & $4(4.40 \%)$ & \\
\hline
\end{tabular}

We have also reported that TIPE2 mRNA was significantly negatively associated with and lesion volumes and NIHSS. Furthermore, TIPE2 mRNA level was significantly negatively associated with TNF- $\alpha$, IFN- $\gamma$ and NF- $\mathrm{\beta} \beta$, but significantly positively associated with IL-6 and IL-10. In addition, hierarchy cluster analysis showed that TIPE2 mRNA has nearest membership with TNF- $\alpha$, followed by IL- 6 , NF-к $\beta$, AP-1, IL-10, IL-1 $\beta$ and IFN- $\gamma$. These results might provide clues for analysis the exact of complex network with TIPE2 and associated cytokine in the early phase of acute ischemic stroke. Although the biological function of TIPE2 on stroke has not been well elucidated, the possible aspects should be considered. First, TIPE2 might be the initiator for the immune response and inflammation in the early stage of acute ischemic stroke. Mice model of ischemic stroke models with knockout of Tipe2 gene has been reported to present the higher ischemic volume and more severe brain impairment than wild type mice [20]. Second, TIPE2 might be a compensatory feedback for the subacute or later stage of acute ischemic stroke [30].Zhang found that inflammation associated with stroke can lead to secondary ischemic injury [31-33]. It has been demonstrated that TIPE2 might inhibit the activation of NF-kB by binding to caspase- 8 in the immune deficiency $[34,35]$. Blockage of TIPE2 might result in the increased levels of interleukin 10, interleukin 6, interleukin 12 and TNF-a. Therefore, current evidence suggested that TIPE2 is involved in the development of acute ischemic stroke. However, the exact mechanism for the biological role of TIPE2 in the acute and later phases of acute ischemic stroke should be well studied in the future.

After the 3-month treatment and follow up, a total of 22 patients died and the mortality rate was $18.13 \%$. We have also demonstrated that TIPE2 mRNA in survivals was significantly higher than that in nonsurvival, as well as the same trend for IL-10. Furthermore, we have found that the medians of TNF- $\alpha$, AP-1, IFN- $\gamma$ and NF- $\alpha \beta$ mRNA levels in survivals were significantly lower than that in nonsurvivals. These results further supported the hypothesis that TIPE2 associated immunity involved in the progression of acute ischemic stroke. In addition, we primarily investigated the possible effects of TIPE2 mRNA and TIPE2 associated cytokines on mortality. Importantly, TIPE2 mRNA showed the greatest OR in all the ORs for IL-1 $\beta$, IL-10, IL-6, NF-k $\beta$, AP-1, IFN- $\gamma$ and TNF- $\alpha$, suggesting that TIPE2 mRNA might be a potential biomarker for the mortality of acute ischemic stroke.

Several limitations should be mentioned in this present study. First, we determined the TIPE2 mRNA using PBMCs, rather than cerebral spinal fluid, which might be more accurate in reflecting the real condition of brain. However, it is not realistic for obtain the cerebral spinal fluid under the emergency condition of acute stroke. Second, this study was also limited by the relatively small number of patients and heathy controls, especially for healthy controls with the matched ratio was less than 1:1. And the patients' samples usually come from our single unit. Therefore, large samples of patients from multiple units might be helpful in the future study. Third, our data came from Chinese only, which might result in the potential of selection bias.

In conclusion, our present study firstly demonstrated that reported that TIPE2 mRNA in patients with acute ischemic stroke was significantly higher that than in healthy controls. TIPE2 mRNA contributed to the immune response of stroke and 
might be a potential biomarker for the mortality of acute ischemic stroke. However, the exact mechanism underlying the biological role of TIPE2 in the acute and later phases of acute ischemic stroke should be well studied in the future.

\section{Abbreviations}

BMI: body mass index; CI: confidence interval; eGFR: estimated glomerular filtration rate; HCY: homocysteine; Hs-CRP: high-sensitivity $\mathrm{C}$ reactive protein; IQR: interquartile range; LACI: lacunar infarct; LDL: low-density lipoprotein; NIHSS: national institutes of health stroke scale; OR: odd ratio; PACI: partial anterior circulation infarct; PBMCs: peripheral blood mononuclear cells; POCI: posterior circulation infarct; RT-PCR: real time quantitative reverse transcriptase polymerase chain reaction; TACI: total anterior circulation infarct; TC: total cholesterol; TG: total triglyceride; TIPE2: Tumor necrosis factor-ainduced protein 8-like 2; FBG: fasting blood glucose; AP-1: Activator protein 1; TNF-a: Tumor Necrosis Factor $\alpha$; IFN- $\gamma$ : interferon $\gamma$; IL-1 $\beta$ : interleukin $1 \beta$; IL-6: interleukin 6; IL-10: interleukin 10; NF-KB: nuclear factor $\mathrm{\kappa B}$; NA: not available.

\section{Acknowledgements}

This work was supported by the grants from the National Natural Science Foundation of China $(81373635,81201287)$ and Key research and development plan of Shandong Province (2016GSF121044).

\section{Competing Interests}

The authors have declared that no competing interest exists.

\section{References}

1. Majersik JJ, Morgenstern LB. Informed consent in acute ischemic stroke: It's on us. Neurology. 2018; 90: 203-4.

2. Drieu A, Levard D, Vivien D, Rubio M. Anti-inflammatory treatments for stroke: from bench to bedside. Ther Adv Neurol Disord. 2018; 11: 1756286418789854

3. Li WX, Qi F, Liu JQ, Li GH, Dai SX, Zhang T, et al. Different impairment of immune and inflammation functions in short and long-term after ischemic stroke. Am J Transl Res. 2017; 9: 736-45.

4. Jones KA, Maltby S, Plank MW, Kluge M, Nilsson M, Foster PS, et al Peripheral immune cells infiltrate into sites of secondary neurodegeneration after ischemic stroke. Brain Behav Immun. 2018; 67: 299-307.

5. Ao LY, Yan YY, Zhou L, Li CY, Li WT, Fang WR, et al. Immune Cells After Ischemic Stroke Onset: Roles, Migration, and Target Intervention. J Mol Neurosci. 2018.

6. Picascia A, Grimaldi V, Iannone C, Soricelli A, Napoli C. Innate and adaptive immune response in stroke: Focus on epigenetic regulation. J Neuroimmunol. 2015; 289: 111-20.

7. Shichita T, Ago T, Kamouchi M, Kitazono T, Yoshimura A, Ooboshi H. Novel therapeutic strategies targeting innate immune responses and early inflammation after stroke. J Neurochem. 2012; 123 Suppl 2: 29-38.

8. Sun H, Gong S, Carmody RJ, Hilliard A, Li L, Sun J, et al. TIPE2, a negative regulator of innate and adaptive immunity that maintains immune homeostasis. Cell. 2008; 133: 415-26.

9. Liu R, Fan T, Geng W, Chen YH, Ruan Q, Zhang C. Negative Immune Regulator TIPE2 Promotes M2 Macrophage Differentiation through the Activation of PI3K-AKT Signaling Pathway. PloS one. 2017; 12: e0170666.

10. Wang Z, Fayngerts S, Wang P, Sun H, Johnson DS, Ruan Q, et al. TIPE2 protein serves as a negative regulator of phagocytosis and oxidative burst during infection. Proc Natl Acad Sci U S A. 2012; 109: 15413-8.
11. Li D, Song L, Fan Y, Li X, Li Y, Chen J, et al. Down-regulation of TIPE2 mRNA expression in peripheral blood mononuclear cells from patients with systemic lupus erythematosus. Clin Immunol. 2009; 133: 422-7.

12. Li F, Zhu X, Yang Y, Huang L, Xu J. TIPE2 Alleviates Systemic Lupus Erythematosus Through Regulating Macrophage Polarization. Cell Physiol Biochem. 2016; 38: 330-9.

13. Fan YC, Zhang YY, Wang N, Sun YY, Wang K. Tumor necrosis factor-alpha-induced protein 8-like 2 (TIPE2) is associated with immune phases of patients with chronic hepatitis B. Oncotarget. 2017; 8: 30781-92.

14. Qian J, Meng Z, Guan J, Zhang Z, Wang Y. Expression and roles of TIPE2 in autoimmune hepatitis. Exp Ther Med. 2017; 13: 942-6.

15. Wang LY, Fan YC, Zhao J, Gao S, Sun FK, Han J, et al. Elevated expression of tumour necrosis factor-alpha-induced protein 8 (TNFAIP8)-like 2 mRNA in peripheral blood mononuclear cells is associated with disease progression of acute-on-chronic hepatitis B liver failure. Journal of viral hepatitis. 2014; 21: 64-73.

16. Lou Y, Sun H, Morrissey S, Porturas T, Liu S, Hua X, et al. Critical roles of TIPE2 protein in murine experimental colitis. J Immunol. 2014; 193: 1064-70.

17. Li T, Wang W, Gong S, Sun H, Zhang H, Yang AG, et al. Genome-wide analysis reveals TNFAIP8L2 as an immune checkpoint regulator of inflammation and metabolism. Molecular immunology. 2018; 99: 154-62.

18. Padmavathi G, Banik K, Monisha J, Bordoloi D, Shabnam B, Arfuso F, et al. Novel tumor necrosis factor-alpha induced protein eight (TNFAIP8/TIPE) family: Functions and downstream targets involved in cancer progression. Cancer Lett. 2018; 432: 260-71.

19. Yin $\mathrm{H}$, Huang $\mathrm{X}$, Tao $\mathrm{M}, \mathrm{Hu} \mathrm{Q}$, Qiu J, Chen W, et al. Adenovirus-mediated TIPE2 overexpression inhibits gastric cancer metastasis via reversal of epithelial-mesenchymal transition. Cancer Gene Ther. 2017; 24: 180-8.

20. Zhang Y, Wei X, Liu L, Liu S, Wang Z, Zhang B, et al. TIPE2, a novel regulator of immunity, protects against experimental stroke. J Biol Chem. 2012; 287: 32546-55.

21. Zhang H, Zhu T, Liu W, Qu X, Chen $Y$, Ren $P$, et al. TIPE2 acts as a negative regulator linking NOD2 and inflammatory responses in myocardial ischemia/reperfusion injury. J Mol Med (Berl). 2015; 93: 1033-43.

22. Boehme AK, Esenwa C, Elkind MS. Stroke Risk Factors, Genetics, and Prevention. Circ Res. 2017; 120: 472-95.

23. Tsivgoulis G, Patousi A, Pikilidou M, Birbilis T, Katsanos AH, Mantatzis M, et al. Stroke Incidence and Outcomes in Northeastern Greece: The Evros Stroke Registry. Stroke. 2018; 49: 288-95.

24. Brott T, Adams HP, Jr., Olinger CP, Marler JR, Barsan WG, Biller J, et al. Measurements of acute cerebral infarction: a clinical examination scale. Stroke. 1989; 20: 864-70.

25. Adams HP, Jr., Bendixen BH, Kappelle LJ, Biller J, Love BB, Gordon DL, et al. Classification of subtype of acute ischemic stroke. Definitions for use in a multicenter clinical trial. TOAST. Trial of Org 10172 in Acute Stroke Treatment. Stroke. 1993; 24: 35-41.

26. Ilzecka J, Stelmasiak Z. [Practical significance of ischemic stroke OCSP (Oxfordshire Community Stroke Project) classification]. Neurol Neurochir Pol. 2000; 34: 11-22.

27. Sims JR, Gharai LR, Schaefer PW, Vangel M, Rosenthal ES, Lev MH, et al. $\mathrm{ABC} / 2$ for rapid clinical estimate of infarct, perfusion, and mismatch volumes. Neurology. 2009; 72: 2104-10.

28. Jiang M, Liu X, Zhang D, Wang Y, Hu X, Xu F, et al. Celastrol treatment protects against acute ischemic stroke-induced brain injury by promoting an IL-33/ST2 axis-mediated microglia/macrophage M2 polarization. J Neuroinflammation. 2018; 15: 78

29. McDonough A, Weinstein JR. Neuroimmune Response in Ischemic Preconditioning. Neurotherapeutics. 2016; 13: 748-61.

30. Lou Y, Liu S, Zhang C, Zhang G, Li J, Ni M, et al. Enhanced atherosclerosis in TIPE2-deficient mice is associated with increased macrophage responses to oxidized low-density lipoprotein. J Immunol. 2013; 191: 4849-57.

31. Amantea D, Nappi G, Bernardi G, Bagetta G, Corasaniti MT. Post-ischemic brain damage: pathophysiology and role of inflammatory mediators. FEBS J. 2009; 276: 13-26.

32. Xia W, Han J, Huang G, Ying W. Inflammation in ischaemic brain injury: current advances and future perspectives. Clin Exp Pharmacol Physiol. 2010; 37: 253-8.

33. Suzuki S, Tanaka K, Suzuki N. Ambivalent aspects of interleukin-6 in cerebral ischemia: inflammatory versus neurotrophic aspects. J Cereb Blood Flow Metab. 2009; 29: 464-79.

34. Chun HJ, Zheng L, Ahmad M, Wang J, Speirs CK, Siegel RM, et al. Pleiotropic defects in lymphocyte activation caused by caspase- 8 mutations lead to human immunodeficiency. Nature. 2002; 419: 395-9.

35. Salmena L, Hakem R. Caspase- 8 deficiency in $\mathrm{T}$ cells leads to a lethal lymphoinfiltrative immune disorder. J Exp Med. 2005; 202: 727-32. 